\title{
Blood biomarkers of insulin resistance in acute stroke patients treated with intravenous thrombolysis: Temporal profile and prognostic value
}

\author{
Ana I. Calleja1", Elisa Cortijo', Pablo García-Bermejo', Javier Reyes RN¹, Jesús F. Bermejo² and M. Fe Muñoz BS², \\ Rosario Fernández-Herranz ${ }^{1}$ and Juan F. Arenillas ${ }^{1}$ \\ *Correspondence: aicsanz@hotmail.com \\ 'Stroke Unit, Department of Neurology. \\ ${ }^{2}$ Biomedic Investigation Unit (IBC). \\ Hospital Clínico Universitario de Valladolid. Department of Medicine, University of Valladolid. Valladolid, Spain. \\ Institutional addresses: Avda. Ramón y Cajal, 3; 47005; Valladolid, Spain.
}

\begin{abstract}
Background: Metabolic syndrome and insulin resistance may hamper the beneficial effect of intravenous thrombolysis in acute ischemic stroke. We investigated the temporal profile and prognostic value of 11 circulating biomarkers of insulin resistance in acute ischemic stroke patients treated with intravenous thrombolysis.

Methods: We performed a prospective study in acute ischemic stroke patients with a middle cerebral artery (MCA) occlusion who received intravenous tissue plasminogen activator (tPA). Measurement of C-Peptide, Ghrelin, Gastricinhibitory-polypeptide (GIP), Glucagon-like-peptide-1 (GLP-1), Glucagon, Insulin, Leptin, Resistin, Visfatin, Interleukin-6 (IL-6) and Tumor-necrosis-factor-alpha (TNF- $\alpha$ ) was performed in three time-points: before tPA-bolus, right after tPAinfusion and at $24 \mathrm{~h}$. Long term clinical outcome, early neurological recovery, MCA-recanalization, infarct volume and hemorrhagic transformation were outcome variables.

Results: Fifty-two patients were included (61\%women, mean-age75). Three months after stroke onset, 24 (47\%) patients were functionally independent. In a multivariate adjusted regression model, GIP level at $1 \mathrm{~h} \geq 109.51 \mathrm{pg} / \mathrm{ml}$ (OR 13.78 [1.38-137.31], $\mathrm{p}=0.02$ ) and GIP level at $24 \mathrm{~h} \geq 82.19 \mathrm{pg} / \mathrm{ml}$ (OR 28.46 [1.09-739.82], $\mathrm{p}=0.04)$ emerged as independent predictors of good outcome. Baseline GIP and 0-1 h increment in IL- 6 and TNF- $\alpha$ were associated with early neurological course. Ghrelin level at $1 \mathrm{~h}$ and $0-24 \mathrm{~h}$ increment in Leptin level were independently associated with a larger infarct volume.

Conclusions: Blood concentration of several molecules reflecting a more pronounced insulin resistance status was associated with a worse outcome in acute ischemic stroke patients treated with intravenous thrombolysis. Noteworthy, a higher GIP level at $1 \mathrm{~h}$ and $24 \mathrm{~h}$ after tPA treatment predicted good long-term outcome.
\end{abstract}

Keywords: Insulin resistance, acute stroke, cytokines

\section{Introduction}

Stroke is a major cause of death and disability worldwide. Acute reperfusion therapies are aimed to reduce the amount of brain infarcted tissue, thus improving stroke outcome. Among reperfusion therapies, intravenous thrombolysis still represents the only treatment that has proven to be safe and effective in randomized clinical trials. These trials have shown that intravenous tissue plasminogen activator (tPA) improves functional outcome in ischemic stroke and that the benefits outweigh the risk for patients who receive treatment within 4.5 hours of symptoms onset. Results from the NINDS trial showed that intravenous alteplase improves functional outcome at three months, if given within 3 hours of symptom onset [1]. The ECASS 3 clinical trial found that intravenous alteplase is beneficial when given from 3 to 4.5 hours after stroke onset [2]. However, the beneficial effect of stroke thrombolysis can be hampered by several local and systemic factors, among which the metabolic syndrome has gained attention recently $[3,4]$.

Our group previously reported that insulin resistance, the proposed key pathophysiological mechanism underlying metabolic syndrome [5], is associated with a worse response to intravenous thrombolysis in acute ischemic stroke [6]. In that study, insulin resistance was measured by means of the HOMA index calculated during admission. This approach has the risk of a confounding effect caused by the deleterious role of fasting glycemia included in the HOMA equation [7]. Therefore, we decided to explore the role of other glycemia-independent markers of insulin resistance in acute ischemic stroke, thus ruling out the potential bias caused by the association between 24 hours-glycemia and stroke outcome [8].

Insulin resistance is associated with an increased release and action of several adipose-derived cytokines, the so-called adipokines. These adipokines have been involved in the impairment of insulin sensitivity and exert important actions 
on vessel function and metabolic regulation, thanks to their autocrine and paracrine function [9]. These molecules affect platelet function, coagulation and fibrinolysis, and their increased release may contribute to a prothrombotic and systemic inflammatory state[10]. Whereas a significant number of studies have examined the association of adipokines with incident coronary heart disease [11,12], only a limited number of studies have so far investigated the role of adipokines in ischemic stroke [13]. Most of these studies have evaluated the association between a single adipokine and the risk of having a ischemic stroke in the future $[14,15]$. However, the role of insulin-resistance-related biomarkers in the response to acute ischemic stroke therapies remains largely unexplored.

Considering our previous research, we designed a prospective study aimed to describe the temporal profile of several insulin-resistance-related molecules during the acute phase of ischemic stroke and to investigate their effect on patients' outcome after intravenous tPA therapy.

\section{Methods \\ Patient selection}

We prospectively studied acute nonlacunar middle cerebral artery (MCA) ischemic stroke patients admitted to our Stroke Unit from September 2009 to July 2011, who had a documented MCA occlusion on prebolus transcranial color coded Duplex (TCCD) examination and fulfilled criteria to receive intravenous thrombolysis according to our institutional protocol. Besides thrombolysis criteria, specific criteria to enter this study were (1) absence of conditions that could affect biomarker levels such as active neoplasm or prior inflammatory diseases, (2) possibility to obtain and process blood samples prior to TPA bolus and at 1 and 24 hours after thrombolysis was started, (3) patient's functional independence prior to stroke, as defined by a modified Rankin scale (mRs) score of 0 or 1 , and (4) informed consent obtained from patient or relatives.

During the study period, 52 ischemic stroke patients with an acute TCCD-documented MCA occlusion and treated with intravenous tPA fulfilled all selection criteria and were included in the study. The study protocol was approved by the local ethics committee.

\section{Clinical assessment}

All included patients underwent medical history, physical examination, routine blood biochemistry and blood count, electrocardiogram (ECG), chest $X$ ray, urgent cervical Duplex ultrasound, transcranial Duplex examinations, and noncontrast brain computed tomography (CT), upon admission to our Stroke Unit. Intravenous thrombolysis was administered in a $0.9 \mathrm{mg} / \mathrm{kg}$ tPA dose as described in Safe Implementation of Thrombolysis in Stroke-Monitoring Study (SITS-MOST) [16]. Prebolus systolic and diastolic blood pressure (BP) values, temperature, and glycemia were determined on admission. Twenty-four hours glycemia were determined in fasting blood sample. Neurologic examinations were performed on admission and periodically during the next $24 \mathrm{~h}$ after the initiation of the thrombolytic infusion. Stroke severity was determined with the National Institutes of Health Stroke Scale (NIHSS) [17]. We defined "early neurological improvement" as a reduction in the total NIHSS score by $\geq 4$ points or the complete resolution of the neurologic deficit at 24 hours, based on the methods used in previous studies [1].

During admission, history of vascular risk factors and vascular disease was obtained. Cerebral CT scans were carried out before tPA bolus and repeated after $24 \mathrm{~h}$, or earlier when neurologic deterioration occurred. Early ischemic changes in each patient's CT were evaluated according to the Alberta Stroke Program Early CT Score (ASPECTS) [18]. This is a 10-point quantitative topographic CT scan score developed to assess early ischemic changes on pretreatment $\mathrm{CT}$ studies in patients with acute ischemic stroke of the anterior circulation. A normal CT scan receives ASPECTS of 10 points, whereas a score of 0 indicates massive involvement throughout the MCA territory. On follow-up CT we measured infarct volume by using the formula for irregular volumes and we also assessed the presence of symptomatic hemorrhagic transformation (SHT) during admission, according to the SITS-MOST definition [19].

Stroke subtypes were classified using modified Trial of Org 10172 in Acute Stroke Treatment (TOAST) criteria [20], in agreement with the results of the additional diagnostic procedures performed (echocardiography, ECG-Holter monitor, special coagulation test, and immunologic study).

Clinical long-term outcome was assessed 90 days after symptoms onset by means of the mRS[21]. A mRS score $\leq 2$ determined on day 90 after stroke onset was considered indicative of good long-term functional outcome.

\section{Laboratory methods}

Blood samples were drawn right before tPA-bolus, right after tPA infusion and 24h after admission to our Stroke Unit. Blood was also obtained from 10 healthy volunteers without history of stroke or other vascular diseases, who served as laboratory controls to obtain reference values. Plasma was collected by centrifugation at $3.000 \mathrm{rpm}$ for $15 \mathrm{~min}$ at $4^{\circ} \mathrm{C}$, aliquoted and stored blind-coded at $-80^{\circ} \mathrm{C}$ until analysis. Biomarker levels in plasma were measured in patients and controls by using the multiplex Bio-Rad assay (Hercules, CA, USA), "Bio-Plex HU Diabetes 12", at the Biomedic Investigation Unit (IBC), HCUV, Valladolid, Spain. This system allows for quantitative measurement of 12 different mediators (C-Peptide, Ghrelin, Gastric inhibitory polypeptide (GIP), Glucagon-like peptide-1 (GLP-1), Glucagon, Insulin, Leptin, Resistin, Visfatin, Interleukin-6 (IL-6), Tumor necrosis factor-alpha (TNF-a) and Plasminogen activator inhibitor-1 (PAI-1)). Concentrations were given in $\mathrm{pg} / \mathrm{ml}$ for all molecules. Determinations were done by duplicate. Mean coefficients of variation were $<10 \%$ in all replicated samples. Results related to PAI- 1 are not shown as they are reserved for another publication using different methodology. 
Transcranial ultrasound assessment of resistance to clot lysis

All extracranial ultrasound imaging and transcranial Duplex were performed with a Toshiba Aplio XG echograph (Toshiba Medical Systems Europe, Zoetermeer, the Netherlands). TCCD examinations were performed in our Stroke Unit, right before tPA infusion to check the existence of MCA occlusion. If the patient had an inappropriate acoustic window, a single bolus of echocontrast agent (Sonovue) was administered. A followup TCCD study was performed by the same neurosonologist $2 \mathrm{~h}$ after intravenous tPA bolus to monitor arterial status. MCA occlusions were defined according to the Thrombolysis in Brain Ischemia (TIBI) grading system [22], which establishes grade 0 (absent), 1 (minimal), 2 (blunted), or 3 (dampened) as indicative of arterial occlusion. Early arterial recanalization was diagnosed when the TIBI pattern reached a 4 or 5 grade in the 2 hours control TCCD examination.

\section{Statistical analysis}

Statistical analyses were performed with the SPSS statistical package (version 18.0; SPSS Inc, Chicago III). Statistical significance for intergroup differences was assessed by the $x^{2}$ test for categorical variables and the Student $t$ test and Mann-Whitney $U$ test for continuous variables. All continuous variables except NIHSS score, ASPECTS score, leukocyte and platelet were normally distributed. Non parametric tests were used for molecule analysis. Protein concentrations required a log transformation to satisfy the linearity assumption. Mediators' levels were first compared between patients and controls using Mann-Whitney U-test. Variation of protein concentration during the first 24 hours was assessed by means of Friedman and Wilcoxon tests. Bonferroni correction was used for multiple comparisons and a probability value $<0.016$ was considered statistically significant.

Long term clinical outcome, early neurological recovery, early MCA recanalization, infarct volume and hemorrhagic transformation were considered outcome variables. The relationship between mediators levels and stroke outcome was analyzed in several steps. First, to evaluate the relationship between every biomarker level (including their variation in concentration from baseline to the 24 hour time-point) and outcome variables, crude logistic regression models were applied. Molecules showing a $p \leq 0.2$ on the respective crude logistic regression analysis were included in a multivariate regression model, and adjustment was done by all baseline variables showing a $p \leq 0.1$ on the respective bivariate analyses. Results of the regression analyses are expressed as odds ratios (ORs) and their corresponding confidence intervals $(\mathrm{Cl})$. Second, receivers operating characteristic (ROC) curves were calculated for molecules showing a $p \leq 0.1$ on the multivariate adjusted logistic regression models, in order to determine their predictive value under the curve as well as to obtain the cut-point that better discriminated between favorable and unfavorable stroke outcome. For all tests, a probability value $<0.05$ was considered statistically significant.

\section{Results}

Descriptive analysis and temporal profile of insulin resistance related-biomarkers

We studied 52 consecutive acute ischemic stroke patients with a documented MCA occlusion treated with intravenous tPA. Of them $32(61.53 \%)$ were female, mean age was $75.38 \pm 8.89$ years and median NIHSS was 15 (9-21). Table 1 summarizes the distribution of demographic characteristics, baseline clinical variables and molecules level.

Table 1: Distribution of demographic characteristics, baseline clinical variables and cytokine levels. Results are mean $\pm S D$, No. (\%), or median (interquartile range), as appropriate. SBP: Systolic Blood pressure. DBP: Diastolic blood pressure. ASPECTS: Alberta Stroke Program Early CT Score.

\begin{tabular}{|c|c|}
\hline \multicolumn{2}{|l|}{ VARIABLE } \\
\hline Sex, female & $32(61.5 \%)$ \\
\hline Age, y & $75.38 \pm 8.89$ \\
\hline Smoking & $11(21.2 \%)$ \\
\hline Hypertension & $32(61.5 \%)$ \\
\hline Diabetes mellitus & $6(11.5 \%)$ \\
\hline Hypercholesterolemia & $15(28.8 \%)$ \\
\hline Cardioembolic etiology & $24(46.2 \%)$ \\
\hline Baseline NIHSS score & $15(9-21)$ \\
\hline Pre-bolus glycemia, mg/dL & $119.07 \pm 27.86$ \\
\hline $24 \mathrm{~h}$ fasting glycemia,mg/dL & $107.25 \pm 33.61$ \\
\hline 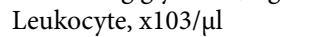 & $8.15(6.43-9.28)$ \\
\hline Platelet, $x 103 / \mu \mathrm{l}$ & $193(165-229)$ \\
\hline Admission SBP, mm Hg & $153.42 \pm 17.16$ \\
\hline Admission DBP, mm Hg & $79.98 \pm 10.67$ \\
\hline ASPECTS & $9(8-10)$ \\
\hline C_Peptide_0h,pg/ml & $1427.10(1161.46-2032.30)$ \\
\hline C_Peptide_1h,pg/ml & $1925.43(1471.33-2818.98)$ \\
\hline C_Peptide_24h,pg/ml & $1649.31(1209.86-2173.72)$ \\
\hline Ghrelin_0h, pg/ml & $62.50(38.77-135.74)$ \\
\hline Ghrelin_1h,pg/ml & $93.99(51.40-156.83)$ \\
\hline Ghrelin_24h,pg/ml & $116.66(84.62-150.83)$ \\
\hline GIP_0h,pg/ml & $46.54(25.44-118.08)$ \\
\hline GIP_1h,pg/ml & $109.51(63.51-194.32)$ \\
\hline GIP_24h, pg/ml & $78.10(58.67-133.88)$ \\
\hline GLP-1_0h, pg/ml & $725.04(545.93-1002.32)$ \\
\hline GLP-1_1h, pg/ml & $920.71(459.09-1550.04)$ \\
\hline GLP-1_24h,pg/ml & $1279.23(1007.16-1892.57)$ \\
\hline Glucagon_0h,pg/ml & $757.57(624.91-855.62)$ \\
\hline Glucagon_1h,pg/ml & $919.35(805.26-1105.59)$ \\
\hline Glucagon_24h,pg/ml & $891.56(805.57-990.46)$ \\
\hline Insulin_0 $\overline{\mathrm{h}}, \mathrm{pg} / \mathrm{ml}$ & $1791.20(1252.83-2731.15)$ \\
\hline Insulin_1h, pg/ml & $3154.96(1559.37-5279.02)$ \\
\hline Insulin_24h,pg/ml & $2945.71(2303.15-4827.09)$ \\
\hline Leptin_0h, pg/ml & $2317.50(1463.35-4120.33)$ \\
\hline Leptin_1h,pg/ml & $2560.31(1370.97-3990.47)$ \\
\hline Leptin_24h,pg/ml & $1933.93(1307.49-5403.32)$ \\
\hline Resistin_0h,pg/ml & $2766.56(1929.42-5640.59)$ \\
\hline Resistin_1h,pg/ml & $3619.16(2090.16-12247.91)$ \\
\hline Resistin_24h,pg/ml & $1816.83(1411.92-3251.75)$ \\
\hline Visfatin_0h, pg/ml & $35.68(35.68-1918.54)$ \\
\hline Visfatin_1h, pg/ml & $1886.38(35.68-7853.48)$ \\
\hline Visfatin_24h,pg/ml & $943.55(12.40-1727.51)$ \\
\hline IL6_0h, pg/ml & $20.17(14.86-31.44)$ \\
\hline IL6_1h, pg/ml & $28.46(19.71-39.57)$ \\
\hline IL6_24h,pg/ml & $32.31(22.63-48.08)$ \\
\hline TNFa_0h,pg/ml & $36.13(26.27-54.19)$ \\
\hline TNFa_1h,pg/ml & $37.20(22.83-66.67)$ \\
\hline TNFa_24h,pg/ml & $46.43(33.71-59.33)$ \\
\hline
\end{tabular}






Studied biomarkers level was higher in stroke patients than in healthy controls for most molecules and in most time-points, with the exception of Leptin. Regarding biomarker variation during the first 24 hours, most molecules experienced a progressive increment, some of them (C-Peptide , GIP, Glucagon, Insulin, Resistin and Visfatin) picking at the first hour and then decreasing until the 24 hour timepoint. The time profile of the studied biomarkers is shown on Figure 1.
No significant correlations were found between the baseline level of any molecule and admission's glycemia. Regarding 24-hours glycemia, significant correlations were found for GIP level at 24 hours $(r=-0.42, p=0.006)$ (Figure 2a), C-Peptide at 24 hours ( $r=-0.35, p=0.02), 24$ - hours Ghrelin ( $r=-0.34$, $p=0.03)$, 24-hours GLP1 ( $r=-0.43, p=0.006)$, 1-hour Resistin $(r=0.37, p=0.01)$ and Glucagon increment during the first $24 \mathrm{~h}$ $(r=0.36, p=0.02)$. 


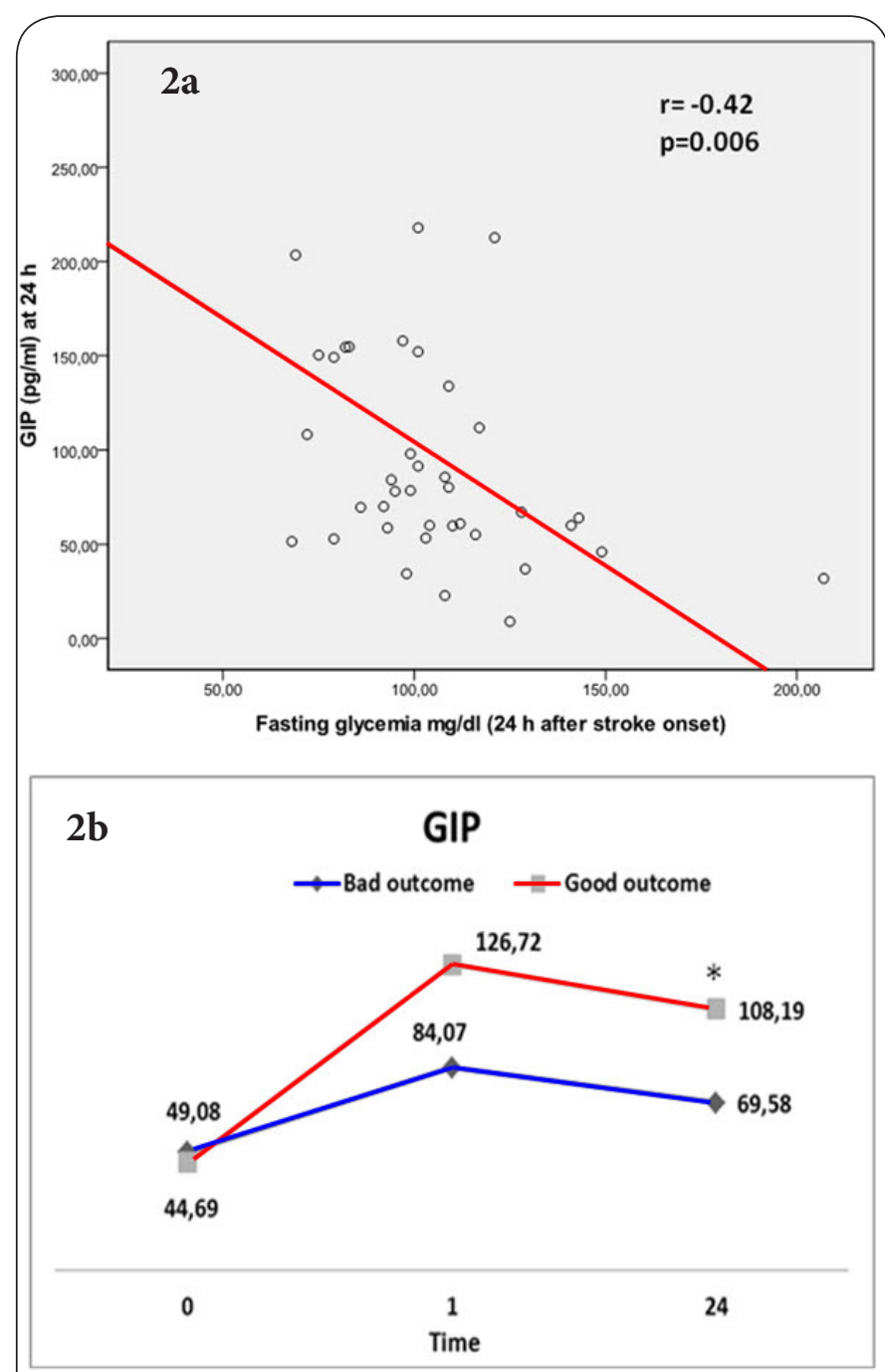

Figure 2: 2a. Correlation between GIP level at 24 hours and fasting glycemia

2b. GIP level and long term clinical outcome. Variation in GIP level attending long-term outcome subgroups.

* Statistically significant $(\mathrm{p}<0.05)$.

\section{Association between molecule concentration and endpoint variables}

Long term clinical outcome

Three months after stroke onset, 24 (47\%) patients had a good outcome (mRS score $\leq 2)$. Bivariate analysis, shown on Table 2, identified higher baseline NIHSS score $(P<0.001)$, lower baseline NCCT ASPECTS $(p=0.002)$ and higher admission DBP $(p=0.02)$ as significantly associated with a long-term poor clinical outcome. The concentration of the following biomarkers, analyzed as continuous variable, was significantly associated with long-term clinical outcome in the bivariate analyses: $24 \mathrm{~h}$-GIP, 1 h-Resistin, 1 h-Visfatin, GIP, Insulin and Leptin variation during the first $24 \mathrm{~h}$, and Visfatin increment during the first hour. These associations did not resist multivariate
Table 2: Results of the bivariate analysis of baseline clinical variables associated with poor long-term clinical outcome. Results are mean $\pm \mathrm{SD}$, No. (\%), or median (interquartile range), as appropriate. SBP: Systolic Blood pressure. DBP: Diastolic blood pressure. ASPECTS: Alberta Stroke Program Early CT Score

\begin{tabular}{llll}
\hline VARIABLE & $\begin{array}{l}\text { Good outcome at } \\
\text { 3 months }(\mathbf{n}=\mathbf{2 4})\end{array}$ & $\begin{array}{l}\text { Poor outcome at } \\
\text { (n=27) }\end{array}$ & Value \\
\hline Sex, female & $13(54.16 \%)$ & $19(70.37 \%)$ & 0.23 \\
Age, y & $76.54 \pm 8.56$ & $74.22 \pm 9.33$ & 0.36 \\
Smoking & $5(20.83 \%)$ & $6(22.22 \%)$ & 0.90 \\
Alcohol & $1(4.16 \%)$ & $3(11.11 \%)$ & 0.24 \\
Hypertension & $15(62.5 \%)$ & $17(62.96 \%)$ & 0.26 \\
Diabetes mellitus & $1(4.16 \%)$ & $5(18.51 \%)$ & 0.11 \\
Hypercholesterolemia & $7(29.16 \%)$ & $8(29.62 \%)$ & 0.97 \\
TOAST category & - & - & 0.12 \\
CE & $8(33.33 \%)$ & $16(59.25 \%)$ & - \\
ATH & $5(20.83 \%)$ & $5(18.51 \%)$ & - \\
IND & $11(45.83 \%)$ & $5(18.51 \%)$ & - \\
Others & $0(0 \%)$ & $1(3.70 \%)$ & - \\
Baseline NIHSS score & $10(6-14)$ & $19(15-22)$ & $<0.001$ \\
Basal glycemia, mg/dL & $111.83 \pm 24.28$ & $125.18 \pm 30.18$ & 0.091 \\
24h fasting glycemia,mg/ \\
dL
\end{tabular}

adjustment for those variables with $p<0.1$ on bivariate analysis (See Supplement table 1). Among molecules showing a $\mathrm{p} \leq 0.1$ on the multivariate adjusted logistic regression model, only $1 \mathrm{~h}$-GIP, $24 \mathrm{~h}$-GIP and $1 \mathrm{~h}$-Visfatin exhibited area under ROC (AUROC) values above 0.6 . A level of $109.5 \mathrm{pg} / \mathrm{ml}$ for $1 \mathrm{~h}-$ GIP and $82.19 \mathrm{pg} / \mathrm{ml}$ for $24 \mathrm{~h}-\mathrm{GIP}$ emerged as the best cutoff values ((sensitivity $71 \%$; specificity $70 \%$ ) (sensitivity $61 \%$; specificity $77 \%$ ) respectively). GIP level at 1 and 24 hour higher than the selected cutoff values emerged as independent predictors of good outcome (OR 13.78 [95\% $\mathrm{Cl} 1.38-137.31], p=0.02$ and $\mathrm{OR} 28.46$ [95\% Cl 1.09-739.82], $p=0.04$ respectively), being these associations independent of admission and 24 hours glycemia. Figure $\mathbf{2 b}$ shows the variation in GIP level attending long-term outcome subgroups.

\section{Early neurological improvement}

Twenty four hours after stroke onset, 21 (40.38\%) patients experienced early clinical improvement. The multiple logistic regression analysis adjusted for those variables with $p<0.1$ on bivariate analysis (platelets $p=0.04$ and admission diastolic 
$\mathrm{BP}(\mathrm{DBP}) \mathrm{p}=0.06)$, identified admission GIP (OR $4.47[95 \% \mathrm{Cl}$ 1.08-18.51], $\mathrm{p}=0.03)$, IL6 (Oh-1h) (OR 0.06 [95\% Cl 0.005-0.73], $\mathrm{p}=0.02)$, and TNF- $\mathrm{a}(\mathrm{Oh}-1 \mathrm{~h})(\mathrm{OR} 0.13$ [95\% $\mathrm{Cl} 0.02-0.91], \mathrm{p}=0.04)$, as significantly associated with neurological improvement. Among molecules showing a $p \leq 0.1$ on the multivariate adjusted logistic regression model, only baseline GIP and 24h-GIP exhibited AUROC values above 0.6. A level of 84.91 $\mathrm{pg} / \mathrm{ml}$ for $24 \mathrm{~h}-\mathrm{GIP}$ emerged as the best cutoff value (sensitivity $55 \%$; specificity $72 \%$ ). GIP level at 24 hour higher than the selected cutoff value was an independent predictor of early neurological recovery (OR $5.76[95 \% \mathrm{Cl} 1.27-26.16], \mathrm{p}=0.02$ ).

\section{Recanalization by TCCD}

Control TCCD to assess MCA status at 2 hours was performed in $41 / 52$ patients. Early MCA recanalization was observed in 15 (36\%). No significant relationship was found between molecules concentration and the probability of MCA recanalization.

\section{Infarct volume}

Median infarct volume measured on follow up CT was $28.8 \mathrm{cc}$ (4.43cc-79cc). Linear regression analysis showed that baseline NIHSS $(p<0.001)$, ASPECTS $(p<0,001), 1$-Ghrelin $(p=0.10)$, $1 \mathrm{~h}-\mathrm{GLP} 1(\mathrm{p}=0.06), 1 \mathrm{~h}-\mathrm{IL}-6(\mathrm{p}=0.10)$ and Leptin increment from $0-24 h(p=0.006)$ were associated with infarct volume. A multiple linear regression analysis adjusted for those variables with $p<0.1$ on bivariate analysis, identified $1 \mathrm{~h}$-Ghrelin (B 46.25 [95\% Cl 2.34-90.16], $\mathrm{p}=0.03$ ), and Leptin increment ( $0 \mathrm{~h}-24 \mathrm{~h}$ ) (OR 58.27 [95\% Cl 6.32-110.22], p=0.02), as independently associated with a larger infarct volume.

\section{Symptomatic hemorrhagic transformation}

Two patients (3.8\%) patients had a SHT. No significant relationship was found between molecule concentration and the probability of SHT.

\section{Discussion}

Among the 11 studied insulin resistance related-biomarkers, we found relevant associations between the plasma level of GIP, leptin, ghrelin, TNF- $\alpha$ and IL- 6 and the oucome variables assessed in consecutive MCA ischemic stroke patients treated with i.v. tPA. Of note, a lower level of GIP measured at 1 and 24 hours after tPA bolus predicted a poorer long-term outcome. These results are in line with previous investigations suggesting that insulin resistance may play a deleterious role in acute ischemic stroke, mediated in part by hampering the therapeutic effect of intravenous thrombolysis.

Regarding the time profile of these molecules during the acute phase of ischemic stroke, we were not able to find previous studies in the literature with which to compare our results. When designing the study, we expected to find at least one molecule not suffering significant changes during the acute phase, which could then serve as an indirect indicator of the patients' insulin resistance status prior to stroke. However, most of the studied biomarkers showed an increase in their plasma level during the first 24 hours after admission and could be therefore influenced by stroke-induced acute phase reaction. Interestingly, the associations with stroke outcome were not found for any of the biomarkers' pre-treatment level, but for the change in the molecule concentration observed during the first 24 hours after treatment onset. The magnitude of this acute change in the biomarkers concentration in response to cerebral ischemia showed a wide interindividual variability across the study sample. We suggest that the observed differences in the molecules' time profile might be influenced by pre-stroke insulin resistence status, although this hypothesis needs to be further clarified.

A higher level of GIP at 1 and 24 hours after tPA bolus was associated with a better long-term outcome after thrombolytic therapy. Moreover, a higher level of GIP at admission and at 24 hours was associated with early neurological recovery. GIP is widely recognized as a physiological incretin hormone, which potently stimulates insulin release depending on glucose level. Its secretion is regulated mainly by the presence of nutrients in the gastrointestinal tract [23], although the mechanisms regulating GIP release in the context of a stress reaction, such as the one triggered by ischemic stroke, are not well known. In animal models, sustained chemical knockout of GIP receptor signaling results in mild impairment of insulin secretion and glucose homeostasis [24]. Consistent with this view, human studies have reported markedly reduced levels of GIP in type 2 diabetic patients[25]. However, little is known about the role of this molecule in critically ill patients, and its potential contribution to the development of acute stress hyperglycemia [26]. In our series, we found that those patients with a less pronounced increase in GIP level during the first 24 hours, showed a higher glycemia at 24 hours. Hyperglycemia is known to be a strong determinant of poor outcome in stroke patients in general [27], and also in ischemic stroke patients treated with intravenous thrombolysis [28]. In this context, not only admission's glycemia predicts stroke outcome, but hyperglycemia observed at any time within the first 48 hours may have a deleterious effect on stroke patients $(5,6)$. In order to explain the independent association found between GIP and outcome, we hypothesize that GIP expression in the setting of acute ischemic stroke might be a part of an insulin-sensitizing response aimed to reduce glucose level, thus counteracting the adverse effect of acute hyperglucemia on stroke outcome. More research is needed to know whether GIP is an active mediator or only an innocent bystander in acute ischemic stroke. If GIP turns to be actively involved in processes determining acute stroke outcome, whether its therapeutic modulation could bring any clinical effect would also deserve further study.

Both leptin and ghrelin were associated with final infarct volume. Leptin is an important adipose derived hormone which regulates energetic intake and expenditure. The potential deleterious role of leptin in acute ischemic stroke, as suggested 
by our finding, is also supported by previous experimental studies. Leptin was shown to promote the expression of plasminogen activator inhibitor- 1 (PAl-1) in an in vitro culture of human vascular endothelial cells [29]. Moreover, leptin administration promoted arterial thrombosis in vivo studies in mice [30]. These prothrombotic effects may be inhibited after leptin neutralizing monoclonal antibody administration, as shown in murine models of arterial injury and pulmonary embolism [31]. In line with this experimental data, clinical studies in human found an association between higher leptin levels and endothelial dysfunction [32]. However, these studies, together with our results, are in disagreement with recent investigations performed in a mice model of transient focal cerebral ischemia showing that peripherally administered leptin decreased infarct volume by reducing oxidative stress and neuronal apoptosis [33]. Regarding ghrelin, our finding seems to be in conflict with what has been reported in the literature. Animal models of permanent focal cerebral ischemia in rats showed that ghrelin treatment results in decreased infarct size and neurological deficit through suppression of inflammation, nNOS activity, and apoptosis [34]. In both animal [35] and human [36] studies of cardiac disease, ghrelin improved left ventricular structure and function, exercise capacity and muscle wasting, suggesting that ghrelin could be a new therapeutic approach for the treatment of cardiac heart failure. The role of leptin and ghrelin in human cerebral ischemia needs to be further clarified.

A higher increase in IL- 6 and TNF- $a$ level during the first hour after thrombolytic treatment was associated with a worse early neurological course. Both IL- 6 and TNF- $a$ are known to be elevated in patients with insulin resistance [9], reflecting the existence of a proinflammatory state. This observation is consistent with previous studies showing an association between these and other inflammatory biomarkers determined during the first 24 hours after stroke onset and the probability of early neurological deterioration [37]. This proinflammatory state associated with insulin resistance [6], among other mechanisms, could contribute to worsen the response to intravenous thrombolysis and stroke outcome in general.

This study has some limitations. First, the final sample was small sized, although highly selected, and therefore our results need to be confirmed in a larger validation sample. Moreover, in the hyperacute stroke setting, the condition of insulin resistance is unknown for the majority of the patients. A larger sample would be also needed to separately evaluate the role of these and other biomarkers in stroke patients with a known history of insulin resistance, such as type 2 diabetics. Second, ultrasound protocol could not be fully accomplished in a significant number of patients, which precluded the selection of early arterial recanalization as a primary outcome variable. Third, other biomarkers associated with metabolic syndrome and insulin resistance were not tested, such as adipokines, coagulation and fibrinolysis factors. Among adipokines, our biomarker panel did not include relevant molecules such as adiponectin. In agreement with our main hypothesis, linking insulin resistance with a poorer stroke outcome, both preclinical studies in rat [38] and mice [39] models of focal cerebral ischemia demonstrated a strikingly positive effect of adiponectin on cerebral flow and infarct size. Moreover, 5-year survival rate after first ever ischemic stroke was found to be higher in patients who had a lower adiponectin level determined within the first 24 hours after stroke onset [40]. Fourth, although arterial recanalization was assessed by TCCD, evaluation of brain reperfusion with neuroimaging would have been desirable.

\section{Conclusions}

In conclusion, our findings support the hypothesis that insulin resistance plays a deleterious role in acute ischemic stroke. A higher level of GIP at 1 and 24 hours after tPA bolus, probably reflecting a more intense insulin-sensitizing response, was associated with a better long-term outcome after thrombolytic therapy. Further studies are needed to elucidate the role of GIP and other insulin-resistance related biomarkers as new therapeutic targets in acute ischemic stroke. After this results, our future research plan may include, among other lines, to evaluate the role of GIP in an animal model of focal cerebral ischemia, and to study the role of insulin resistance in acute stroke patients treated with endovascular reperfusion therapies.

\section{Additional file}

\section{Supplement Table}

\section{Competing interests}

The authors declare that they have no competing interests.

\section{Authors' contributions}

A.I.C. contributed to the study design, patient selection, clinical work, neurosonology, data collection, analysis and interpretation, and writing of the manuscript. E.C. and P.G.-B. contributed to patient selection, clinical work, neurosonology, and data collection. J.R. contributed to blood sampling and laboratory work. J.F.B. contributed to laboratory work and analysis. M.F.M. contributed to analysis. R.F.-H. contributed comments to the manuscript. J.F.A. contributed to the study design, patient selection, clinical work, neurosonology, data collection, analysis and interpretation, and writing of the manuscript.

\section{Acknowledgement and funding}

The authors thank Rosa Alcaide and Edita Sánchez on behalf of the nursing staff of the Stroke Unit, without whom completion of this study would have never been possible. A.I.C. was the recipient of a research grant from Instituto de Salud Carlos III (Río Hortega program), Ministery of Science, Spain (2008-2011), which was cofounded between Instituto de Salud Carlos III and Hospital Clínico Universitario, Salud Castilla y León (SACYL); Deparment of Health, Castilla y León (SACYL); Gerencia Regional de Salud, Castilla y León (SACYL). 


\section{Publication history}

Received: 19-Nov-2012 Revised: 29-Dec-2012

Accepted: 3-Jan-2013 Published: 18-Jan-2013

\section{References}

1. Tissue plasminogen activator for acute ischemic stroke. The National Institute of Neurological Disorders and Stroke rt-PA Stroke Study Group. N Engl J Med 1995, 333:1581-7. | Article

2. Hacke W, Kaste M, Bluhmki E, Brozman M, Davalos A, Guidetti D, Larrue V, Lees KR, Medeghri Z, Machnig T, Schneider D, von Kummer R, Wahlgren N, Toni D: Thrombolysis with alteplase 3 to 4.5 hours after acute ischemic stroke. N Engl J Med 2008, 359:1317-1329. | Article | PubMed

3. Arenillas JF, Ispierto L, Millan M, Escudero D, Perez de la Ossa N, Dorado L, Guerrero C, Serena J, Castillo J, Davalos A: Metabolic syndrome and resistance to IV thrombolysis in middle cerebral artery ischemic stroke. Neurology 2008, 71:190-195. | Article | PubMed

4. Arenillas JF, Sandoval P, Perez de la Ossa N, Millan M, Guerrero C, Escudero D, Dorado L, Lopez-Cancio E, Castillo J, Davalos A: The metabolic syndrome is associated with a higher resistance to intravenous thrombolysis for acute ischemic stroke in women than in men. Stroke 2009, 40:344-349. | Article | PubMed

5. Kahn R, Buse J, Ferrannini E, Stern M: The metabolic syndrome: time for a critical appraisal: joint statement from the American Diabetes Association and the European Association for the Study of Diabetes. Diabetes Care 2005, 28:2289-2304. | Article | PubMed

6. Calleja Al, Garcia-Bermejo P, Cortijo E, Bustamante R, Rojo Martinez E, Gonzalez Sarmiento E, Fernandez-Herranz R, Arenillas JF: Insulin resistance is associated with a poor response to intravenous thrombolysis in acute ischemic stroke. Diabetes Care 2011, 34:24132417. | Article | PubMed

7. Natarajan S, Siddiqui A, Chaudhuri A, Dandona P: Comment on: Calleja et al. insulin resistance is associated with a poor response to intravenous thrombolysis in acute ischemic stroke. Diabetes Care 2011;34:2413-2417. Diabetes Care 2012, 35:e49; author reply e50. | Article I PubMed

8. Fuentes B, Castillo J, San Jose B, Leira R, Serena J, Vivancos J, Davalos $A$, Nunez AG, Egido J, Diez-Tejedor E: The prognostic value of capillary glucose levels in acute stroke: the GLycemia in Acute Stroke (GLIAS) study. Stroke 2009, 40:562-568. | Article | PubMed

9. Gnacinska M, Malgorzewicz S, Stojek M, Lysiak-Szydlowska W, Sworczak $\mathrm{K}$ : Role of adipokines in complications related to obesity: a review. $A d v$ Med Sci 2009, 54:150-157. | Article | PubMed

10. Schafer K, Konstantinides S: Adipokines and thrombosis. Clin Exp Pharmacol Physiol 2011, 38:864-871. | Article | PubMed

11. Luc G, Empana JP, Morange P, Juhan-Vague I, Arveiler D, Ferrieres $J$, Amouyel P, Evans A, Kee F, Bingham A, Machez E, Ducimetiere P: Adipocytokines and the risk of coronary heart disease in healthy middle aged men: the PRIME Study. Int J Obes (Lond) 2010, 34:118-126. | Article | PubMed

12. Sattar N, Wannamethee G, Sarwar N, Chernova J, Lawlor DA, Kelly A, Wallace AM, Danesh J, Whincup PH: Leptin and coronary heart disease: prospective study and systematic review. J Am Coll Cardiol 2009, 53:167-175. | Article | PubMed

13. Prugger $C$, Luc $G$, Haas B, Arveiler D, Machez E, Ferrieres J, Ruidavets $J B$, Bingham A, Montaye M, Amouyel P, Yarnell J, Kee F, Ducimetiere $P$, Empana JP: Adipocytokines and the risk of ischemic stroke: the PRIME Study. Ann Neurol 2012, 71:478-486. | Article | PubMed

14. Matsumoto M, Ishikawa S, Kajii E: Association of adiponectin with cerebrovascular disease: a nested case-control study. Stroke 2008, 39:323-328. | Article | PubMed

15. Weikert C, Westphal S, Berger K, Dierkes J, Mohlig M, Spranger J, Rimm $E B$, Willich SN, Boeing $\mathrm{H}$, Pischon T: Plasma resistin levels and risk of myocardial infarction and ischemic stroke. J Clin Endocrinol Metab 2008, 93:2647-2653. | Article | PubMed

16. Wahlgren N, Ahmed N, Eriksson N, Aichner F, Bluhmki E, Davalos A,
Erila T, Ford GA, Grond M, Hacke W, Hennerici MG, Kaste M, Kohrmann $M$, Larrue V, Lees KR, Machnig T, Roine RO, Toni D, Vanhooren G: Multivariable analysis of outcome predictors and adjustment of main outcome results to baseline data profile in randomized controlled trials: Safe Implementation of Thrombolysis in Stroke-MOnitoring STudy (SITS-MOST). Stroke 2008, 39:3316-3322. | Article | PubMed

17. Brott T, Adams HP, Jr., Olinger CP, Marler JR, Barsan WG, Biller J, Spilker J, Holleran R, Eberle R, Hertzberg V, et al.: Measurements of acute cerebral infarction: a clinical examination scale. Stroke 1989, 20:864870. | Article | PubMed

18. Barber PA, Demchuk AM, Zhang J, Buchan AM: Validity and reliability of a quantitative computed tomography score in predicting outcome of hyperacute stroke before thrombolytic therapy. ASPECTS Study Group. Alberta Stroke Programme Early CT Score. Lancet 2000, 355:1670-1674. | Article | PubMed

19. Wahlgren N, Ahmed N, Davalos A, Ford GA, Grond M, Hacke W, Hennerici MG, Kaste M, Kuelkens S, Larrue V, Lees KR, Roine RO, Soinne L, Toni D, Vanhooren G: Thrombolysis with alteplase for acute ischaemic stroke in the Safe Implementation of Thrombolysis in Stroke-Monitoring Study (SITS-MOST): an observational study. Lancet 2007, 369:275-282. | Article | PubMed

20. Adams HP, Jr., Bendixen BH, Kappelle LJ, Biller J, Love BB, Gordon DL, Marsh EE, 3rd: Classification of subtype of acute ischemic stroke. Definitions for use in a multicenter clinical trial. TOAST. Trial of Org 10172 in Acute Stroke Treatment. Stroke 1993, 24:35-41. | Article | PubMed

21. van Swieten JC, Koudstaal PJ, Visser MC, Schouten HJ, van Gijn J: Interobserver agreement for the assessment of handicap in stroke patients. Stroke 1988, 19:604-607. | Article | PubMed

22. Demchuk AM, Burgin WS, Christou I, Felberg RA, Barber PA, Hill MD, Alexandrov AV: Thrombolysis in brain ischemia (TIBI) transcranial Doppler flow grades predict clinical severity, early recovery, and mortality in patients treated with intravenous tissue plasminogen activator. Stroke 2001, 32:89-93. | Article | PubMed

23. Meier JJ, Nauck MA, Kranz D, Holst JJ, Deacon CF, Gaeckler D, Schmidt WE, Gallwitz B: Secretion, degradation, and elimination of glucagonlike peptide 1 and gastric inhibitory polypeptide in patients with chronic renal insufficiency and healthy control subjects. Diabetes 2004 53:654-662. | Article | PubMed

24. Irwin N, Gault VA, Green BD, Greer B, McCluskey JT, Harriott P, O'Harte FP, Flatt PR: Effects of short-term chemical ablation of the GIP receptor on insulin secretion, islet morphology and glucose homeostasis in mice. Biol Chem 2004, 385:845-852. | Article | PubMed

25. Holst JJ, Vilsboll T, Deacon CF: The incretin system and its role in type 2 diabetes mellitus. Mol Cell Endocrinol 2009, 297:127-136. | Article | PubMed

26. Llompart-Pou JA, Fernandez-de-Castillo AG, Burguera B, PerezBarcena J, Marse P, Rodriguez-Yago M, Barcelo A, Raurich JM: Stress hyperglycaemia in critically ill patients: potential role of incretin hormones; a preliminary study. Nutr Hosp 2012, 27:130-137. | Article I PubMed

27. Allport L, Baird T, Butcher K, Macgregor L, Prosser J, Colman P, Davis S: Frequency and temporal profile of poststroke hyperglycemia using continuous glucose monitoring. Diabetes Care 2006, 29:1839-1844. | Article I PubMed

28. Alvarez-Sabin J, Molina CA, Montaner J, Arenillas JF, Huertas R, Ribo M, Codina A, Quintana M: Effects of admission hyperglycemia on stroke outcome in reperfused tissue plasminogen activator--treated patients. Stroke 2003, 34:1235-1241. | Article | PubMed

29. Singh P, Peterson TE, Barber KR, Kuniyoshi FS, Jensen A, Hoffmann M, Shamsuzzaman AS, Somers VK: Leptin upregulates the expression of plasminogen activator inhibitor-1 in human vascular endothelial cells. Biochem Biophys Res Commun 2010, 392:47-52. | Article | PubMed Abstract| PubMed Full Text

30. Bodary PF, Gu S, Shen Y, Hasty AH, Buckler JM, Eitzman DT: Recombinant leptin promotes atherosclerosis and thrombosis in apolipoprotein E-deficient mice. Arterioscler Thromb Vasc Biol 2005, 25:e119-122. | Article | PubMed 
Calleja et al. Journal of Diabetes Research and Clinical Metabolism 2013, http://www.hoajonline.com/journals/pdf/2050-0866-2-2.pdf

31. Konstantinides S, Schafer K, Neels JG, Dellas C, Loskutoff DJ: Inhibition of endogenous leptin protects mice from arterial and venous thrombosis. Arterioscler Thromb Vasc Biol 2004, 24:2196-2201. | Article | PubMed

32. Leung YM, Kwan CY: Dual vascular effects of leptin via endothelium: hypothesis and perspective. Chin J Physiol 2008, 51:1-6. | PDF | PubMed

33. Zhang JY, Jr., Si YL, Liao J, Yan GT, Deng ZH, Xue H, Wang LH, Zhang $\mathrm{K}$ : Leptin administration alleviates ischemic brain injury in mice by reducing oxidative stress and subsequent neuronal apoptosis. J Trauma Acute Care Surg 2012, 72:982-991. | Article | PubMed

34. Cheyuo C, Wu R, Zhou M, Jacob A, Coppa G, Wang P: Ghrelin suppresses inflammation and neuronal nitric oxide synthase in focal cerebral ischemia via the vagus nerve. Shock 2011, 35:258-265. | Article | PubMed

35. Nagaya N, Uematsu M, Kojima M, Ikeda Y, Yoshihara F, Shimizu W, Hosoda H, Hirota Y, Ishida H, Mori H, Kangawa K: Chronic administration of ghrelin improves left ventricular dysfunction and attenuates development of cardiac cachexia in rats with heart failure. Circulation 2001, 104:1430-1435. | Article | PubMed

36. Nagaya N, Moriya J, Yasumura Y, Uematsu M, Ono F, Shimizu W, Ueno $\mathrm{K}$, Kitakaze M, Miyatake K, Kangawa K: Effects of ghrelin administration on left ventricular function, exercise capacity, and muscle wasting in patients with chronic heart failure. Circulation 2004, 110:3674-3679. I Article I PubMed

37. Vila N, Castillo J, Davalos A, Chamorro A: Proinflammatory cytokines and early neurological worsening in ischemic stroke. Stroke 2000, 31:23252329. | Article | PubMed

38. Chen B, Liao WQ, Xu N, Xu H, Wen JY, Yu CA, Liu XY, Li CL, Zhao SM, Campbell W: Adiponectin protects against cerebral ischemiareperfusion injury through anti-inflammatory action. Brain Res 2009, 1273:129-137. | Article | PubMed

39. Nishimura M, Izumiya Y, Higuchi A, Shibata R, Qiu J, Kudo C, Shin HK, Moskowitz MA, Ouchi N: Adiponectin prevents cerebral ischemic injury through endothelial nitric oxide synthase dependent mechanisms. Circulation 2008, 117:216-223. | Article | PubMed

40. Efstathiou SP, Tsioulos DI, Tsiakou AG, Gratsias YE, Pefanis AV, Mountokalakis TD: Plasma adiponectin levels and five-year survival after first-ever ischemic stroke. Stroke 2005, 36:1915-1919. | Article | PubMed

\section{Citation:}

Calleja A I, Cortijo E, García-Bermejo P, Reyes J R N, Bermejo J F, Muñoz M F, Fernández-Herranz R and Arenillas J F: Blood biomarkers of insulin resistance in acute stroke patients treated with intravenous thrombolysis: Temporal profile and prognostic value. Journal of Diabetes Research and Clinical Metabolism 2013, 2:2.

http://dx.doi.org/10.7243/2050-0866-2-2 